University of Nebraska - Lincoln

DigitalCommons@University of Nebraska - Lincoln

The Nebraska Educator: A Student-Led Journal

Department of Teaching, Learning and Teacher

Education

$10-2021$

\title{
The Effects of Self-Regulated Strategy Development on Students with Emotional/Behavioral Disorders: A Literature Review
}

Danika Lang

University of Nebraska-Lincoln, dlang8092@gmail.com

Follow this and additional works at: https://digitalcommons.unl.edu/nebeducator

Part of the Special Education and Teaching Commons

Lang, Danika, "The Effects of Self-Regulated Strategy Development on Students with Emotional/ Behavioral Disorders: A Literature Review" (2021). The Nebraska Educator: A Student-Led Journal. 55. https://digitalcommons.unl.edu/nebeducator/55

This Article is brought to you for free and open access by the Department of Teaching, Learning and Teacher Education at DigitalCommons@University of Nebraska - Lincoln. It has been accepted for inclusion in The Nebraska Educator: A Student-Led Journal by an authorized administrator of DigitalCommons@University of Nebraska - Lincoln. 


\title{
The Effects of Self-Regulated Strategy Development on Students with Emotional/Behavioral Disorders: A Literature Review
}

\author{
Danika Lang \\ Department of Special Education and Communication Disorders \\ University of Nebraska-Lincoln
}

\begin{abstract}
Students identified with or at risk for emotional/behavioral disorders (EBD) face a number of challenges, both academic and behavioral (Trout et al., 2003). Individuals in this disability category especially struggle due to their challenges with self-regulation skills. These difficulties make it strenuous for students with EBD to regulate their thoughts, feelings, actions, and environments that may serve as distractions when attempting to attend to key learning tasks, including written expression. Self-regulated strategy development (SRSD) is a general framework of intervention designed to guide students through the complex process of writing while embedding necessary strategy instruction in self-monitoring, self-instruction, goal setting, and self-reinforcement (Harris \& Graham, 1996). In this literature review, I examine ten studies of the efficacy of SRSD strategy instruction for students identified with or at risk of EBD. Based on the evidence provided by these studies, I venture to make the claim that SRSD is a highly effective writing intervention for students with EBD across grade levels, writing genres, namely narrative, informative, and persuasive, and educational settings such as public schools, specialized private schools, and residential treatment facilities (RTFs).
\end{abstract}

Keywords: emotional/behavioral disorders, self-regulated strategy development, writing 
THE NEBRASKA EDUCATOR, VOLUME 6

\section{Defining Self-Regulated Strategy Development}

One of the primary challenges of students identified with or at risk of emotional/behavioral disorders (EBD) is self-regulation. This population of students has difficulty monitoring their thoughts, feelings, and actions as well as regulating their physical environments (Little et al., 2010). These challenges with self-regulation skills may typically present themselves in one of two ways. Students with EBD may exhibit patterns of either externalizing or internalizing behavior. Students with externalizing behavior patterns tend to be more readily diagnosed than their peers with internalizing behavior patterns because their disability usually manifests itself as outward displays of disruptive behavior or aggression. Students with internalizing behavior patterns, on the other hand, often struggle with more internal difficulties such as anxiety and depression (Gresham et al., 1999), leading this subgroup of students with EBD to more frequently remain undiagnosed.

Self-regulated strategy development (SRSD) is a general framework of intervention designed to guide students through the complex process of writing. As reflected in the name, strategies in self-regulatory procedures such as self-monitoring, self-instruction, and selfreinforcement are embedded within a broader context of writing composition instruction (Harris \& Graham, 1996). Students are taught a general planning strategy that enables them to select a writing topic, organize their thought process by taking notes in a graphic organizer, and then expand upon their notes to fully develop their ideas.

The general planning strategy is taught first with explicit modeling, then guided practice, and eventually independent practice so students can generalize the strategy to different writing genres (What Works Clearinghouse, 2017). The general planning strategy is accompanied by genre-specific strategy instruction that guides students through the process of composing 


\section{THE NEBRASKA EDUCATOR, VOLUME 6}

different types of writing. This design allows students to grow in their capabilities to express themselves through a variety of writing genres such as informative, narrative, and persuasive writing while at the same time strengthening their capacity to independently monitor their progress as they write. SRSD provides embedded instruction in self-regulation skills so that students can eventually implement the strategies without teacher guidance. This particular intervention framework may be particularly well-suited for individuals with EBD because it targets their inability to self-regulate while providing supplementary support in a fundamental academic skill that they often struggle with, namely, written expression.

Originally designed as an intervention for students with learning disabilities and struggling writers, SRSD is now recognized as an evidence-based practice for improving the composition and self-regulation skills for a broad range of students, including typicallydeveloping learners (Graham et al., 2012). In this review of the literature, I make the case that self-regulated strategy development is an effective academic intervention for students identified with or at risk of EBD. In addition, I provide evidence that the benefits of the intervention for this population remain fairly consistent across several writing genres, including informative, persuasive, and narrative, both elementary and secondary grade levels, and different educational settings including typical public schools, private facilities specifically designed to teach students with EBD, and residential treatment facilities (RTFs).

Regardless of the writing genre being taught, SRSD is generally made up of six stages: 1.) Develop background knowledge, 2.) Discuss it, 3.) Model it, 4.) Memorize it, 5.) Support it, and 6.) Independent performance (Harris \& Graham, 1996). This process makes up the general framework of the intervention and allows it to be applied flexibly not only to writing instruction but to other academic skills as well (What Works Clearinghouse, 2017). As instructors and 


\section{THE NEBRASKA EDUCATOR, VOLUME 6}

students progress through each stage, scaffolds are put in place to support acquisition of the particular strategy mnemonics as well as the application of these strategies to their own writing. These stages are designed to provide explicit writing lessons to students, with the primary responsibility of instruction beginning initially with the teacher and gradually transferring over to the student as the strategy is internalized. Additionally, supports such as graphic organizers, transition word lists, and examples of self-statements to provide positive reinforcement are progressively faded. The purpose of this is to encourage students to regulate the writing process themselves without the help of external prompts.

\section{SRSD for Students with Emotional/Behavioral Disorders}

In terms of studying the efficacy of SRSD for students with emotional and/or behavioral concerns, the literature generally divides this population into several groups. These include students who have been identified with EBD, those who present significant levels of internalizing or externalizing behaviors and are therefore at risk, or a mixture of students identified and at risk. Seven of the ten studies covered in this literature review examined the outcomes of SRSD for students who have been identified with EBD (Ennis et al., 2015; Mastropieri et al., 2009; Mastropieri et al., 2014; Ennis, 2016; Garwood et al., 2019; Adkins \& Gavins, 2012; Ennis, Jolivette, \& Boden, 2013). All seven studies demonstrated significant gains in writing achievement for students with EBD, specifically in the areas of total number of essay elements included (Ennis et al., 2015; Mastropieri et al., 2009; Ennis, 2016; Garwood et al., 2019; Adkins \& Gavins, 2012; Ennis, Jolivette, \& Boden, 2013), holistic quality (Ennis et al., 2015; Mastropieri et al., 2009; Mastropieri et al., 2014; Ennis, 2016; Garwood et al., 2019; Adkins \& Gavins, 2012; Ennis, Jolivette \& Boden, 2013), and overall length (Mastropieri et al., 
THE NEBRASKA EDUCATOR, VOLUME 6

2014; Ennis, 2016; Garwood et al., 2019; Adkins \& Gavins, 2012; Ennis, Jolivette, \& Boden. 2013).

Two additional studies examined outcomes of SRSD for students with internalizing or externalizing behavior patterns (Little et al., 2010; Lane et al., 2010), while one looked at a mixed sample of students identified and those at risk (Mason \& Shriner, 2008). The sample of mixed participants showed moderate gains in inclusion of essay parts as well as substantial gains in overall quality, total number of words written, and number of transition words used. The gains in quality, length, and transition words remained consistent as students progressed from baseline to post-instruction and maintenance phases of assessment (Mason \& Shriner, 2008). For students identified as at risk, SRSD demonstrated a positive effect for those with both internalizing and externalizing behavior patterns. Both groups of students showed gains in terms of their number of story (Lane et al., 2010) and persuasive elements, respectively (Little et al., 2010).

In terms of design, eight of the ten studies employed either a multiple probe (Little et al., 2010; Lane et al., 2010; Mason \& Shriner, 2008), multiple baseline (Mastropieri et al., 2009), or multiple probes, multiple baseline single-subject design (Mastropieri et al., 2014; Ennis, 2016; Garwood et al., 2019; Adkins \& Gavins, 2012). Although the remaining two studies utilized some variation of group design (Ennis et al., 2015; Ennis, Jolivette, \& Boden, 2013), the effect of the intervention on students both identified or at risk for EBD was a remarkably positive one from baseline to maintenance or pretest to posttest.

These gains in writing achievement also remained fairly consistent when comparing the writing performance of students at the elementary and secondary grade levels. In terms of age range, the studies were evenly divided between students in grades $\mathrm{K}$ through six (Little et al., 2010; Lane et al., 2010; Adkins \& Gavins, 2012; Ennis, Jolivette, \& Boden, 2013; Mason \& 
THE NEBRASKA EDUCATOR, VOLUME 6

Shriner, 2008) and those in grades seven through twelve (Ennis et al., 2015; Mastropieri et al., 2009; Mastropieri et al., 2014; Ennis, 2016; Garwood et al., 2019). In the reviewed studies, elementary school students were taught how to use the POW and TREE (Little et al., 2010; Mason \& Shriner, 2008) and STOP and DARE (Ennis, Jolivette, \& Boden, 2013) strategies of SRSD to guide the composition of their persuasive writing. The overarching purpose of the strategy mnemonics included in SRSD is to provide a salient way for students to ensure that their writing has all the necessary components such as a topic sentence and supporting evidence in a persuasive essay or the main characters and setting for a narrative piece of writing. With the POW and TREE mnemonics, students are equipped with a general planning strategy (POW) where P stands for "Pick my idea," O for "Organize my notes," and W for "Write and say more." TREE is an additional strategy mnemonic that is specifically geared towards the persuasive writing genre. The $\mathrm{T}$ in TREE stands for "Topic sentence" in which the primary argument is stated, R for "Reasons, three or more" to provide supporting evidence for the argument, the first E for "Ending" to make sure the essay has a succinct conclusion, and the second E for "Examine" the writing to make sure all necessary parts were included (Harris et al., 2006).

\section{Effects on Elementary Students}

For the elementary students identified or at risk of EBD, instruction in the POW and TREE strategy mnemonics resulted in an increase in the number of persuasive elements included from baseline to post-instruction. This much was true for students with internalizing behavior patterns in the study conducted by Little et al. (2010). Additionally, students with externalizing behavior patterns (Little et al., 2010) and five of the six students identified with EBD in a study by Mason \& Shriner (2008) showed gains in number of persuasive elements, overall quality, and length of essays assessed in post-instruction and maintenance phases. 
THE NEBRASKA EDUCATOR, VOLUME 6

The STOP and DARE strategy mnemonics take a slightly different approach to the guidance of persuasive writing, with a greater emphasis on the inclusion of counterarguments. The S in STOP stands for "Suspend judgment," T for "Take a side," O for "Organize ideas," and P for "Plan more as you write." The D in DARE stands for "Develop your topic sentence," A for "Add supporting ideas," R for "Reject at least one argument for the other side," and E for "End with a conclusion (Harris et al., 2008). This persuasive writing strategy provides an additional challenge for students to consider the lines of reasoning for an opposite viewpoint and then to provide an effective argument for their own opinion in the face of strong counterarguments. In their study of the impact of the STOP and DARE strategy mnemonics for elementary students with EBD, Ennis, Jolivette, \& Boden (2013) found that participants in the experimental group outperformed those in the control group on measures of the number of persuasive elements included, overall quality, and total words written with post-instruction effect sizes of $1.35,1.06$, and 1.27 , respectively.

For narrative writing (Adkins \& Gavins, 2012; Lane et al., 2010) students were taught to use the POW and WWW, What=2, How=2 strategies of SRSD. The POW mnemonic remains the same and serves as a general planning strategy while WWW What $=2$, How $=2$ is a genrespecific strategy for narrative writing. In using this strategy mnemonic, students are challenged to provide answers to the questions: "Who is the main character?" "When does the story take place?" "Where does the story take place?" "What does the main character do or want to do?" "What happens when the main character tries to achieve their goal?" "How does the story end?" and "How does the main character feel?" (Harris et al., 2008). Following these guidelines reminds students to include all of the key components of narrative writing including characters and setting as well as the essential elements of plot, namely exposition, rising action, climax, 
THE NEBRASKA EDUCATOR, VOLUME 6

falling action, and resolution. Overall, instruction in the POW and WWW, What $=2$, How $=2$ strategy mnemonics resulted in an increased number of story elements included in the narrative writing of students at risk for EBD who demonstrated externalizing behavior patterns (Lane et al., 2010). Additionally, gains were demonstrated in story length as well as quality for four of the five students with internalizing behavior patterns. These increases in number of story elements, length, and overall quality were consistent for elementary students identified with EBD (Adkins \& Gavins, 2012).

\section{Effects on Secondary Students}

When looking at the effects of SRSD on secondary students with EBD, the outcomes are similarly positive. The key difference between studies involving secondary versus elementary students is the genre selected for instruction. Of the reviewed studies, one taught students to summarize informational text (Ennis, 2016) while the other four provided instruction in persuasive writing using the STOP and DARE (Ennis et al., 2015) or the POW and TREE (Garwood et al., 2019; Mastropieri et al., 2009; Mastropieri et al., 2014) strategy mnemonics outlined above. Students were taught to summarize informational text in social studies using the TWA+PLANS SRSD strategy mnemonic. The TWA portion of the strategy provides a framework for organizing ideas while reading informational text, where T stands for "Think before reading," W for "Think while reading," and A for "Think after reading." To complement the reading aspect, the PLANS portion of the strategy targets formulation of a written summary

from the information read. In the PLANS mnemonic, P stands for "Pick goals," L for "List ways to meet goals," A and N for "And make notes," and S for "Sequence notes."

In the study that investigated the effectiveness of this strategy on secondary students' ability to summarize informational text, the authors found that participants increased in number 
THE NEBRASKA EDUCATOR, VOLUME 6

of summary elements, holistic quality, and total words written from baseline to post-instruction (Ennis, 2016). However, due to the small sample size of this study ( $n=3)$ and its lack of replication, these findings must be interpreted with caution. In order to more clearly show a causal relationship between SRSD instruction and gains in informational text writing for this population, additional generalization to other groups of students with EBD is required. In terms of the effectiveness of the POW and TREE strategies on the persuasive writing of secondary students with EBD, there was only a uniform finding of increased overall quality across the three included studies (Garwood et al., 2019; Mastropieri et al., 2009; Mastropieri et al., 2014). Additionally, Garwood et al. (2019) and Mastropieri et al. (2009) found an increase in number of persuasive elements included. These conclusions are also limited due to a total sample size of 35 students across the three studies examined in this literature review. Finally, for students instructed in the STOP and DARE persuasive writing strategies, the authors found statistically significant gains in number of persuasive elements, overall quality, and number of correct word sequences (CWS) from pretest to posttest. These gains in persuasive writing measures generalized to gains in their performance on the Writing Fluency and Writing Samples subtests of the Woodcock-Johnson Tests of Achievement, Third Edition, with moderate and large descriptive effect sizes, respectively (Ennis et al., 2015).

\section{Effects for Different Writing Genres}

In a breakdown of studies by genre, the effects of SRSD strategy instruction are similarly positive for students with EBD, although there were substantially more studies across grade levels and educational settings that provided evidence of the positive effects of persuasive writing instruction $(n=7)$. With a total sample size of 114 participants across seven studies, five of which were single-subject design studies, more credence may be afforded to the findings 
THE NEBRASKA EDUCATOR, VOLUME 6

surrounding these strategies (Little et al., 2010; Mason \& Shriner, 2008; Ennis, Jolivette, \& Boden, 2013; Garwood et al., 2019; Ennis et al., 2015; Mastropieri et al., 2009; Mastropieri et al., 2014). For participants in all but one of the seven studies that taught persuasive writing strategies (Mastropieri et al., 2014), those who received the treatment condition of SRSD demonstrated gains in number of persuasive elements included from baseline to post-instruction. Further, all participants with the exception of those exhibiting internalizing behavior patterns in the Little et al. study (2010) showed improvement in overall quality from baseline scores, with some or all of the participants in four of the seven studies indicating additional gains in terms of essay length (Little et al., 2010; Mason \& Shriner, 2008; Ennis, Jolivette, \& Boden, 2013; Garwood et al., 2019).

The three remaining studies included analyses of the effectiveness of narrative $(n=2)$ and informative $(n=1)$ writing strategies using the framework of SRSD with total sample sizes of three, 13, and three, respectively (Adkins \& Gavins, 2012; Lane et al., 2010; Ennis, 2016). For the studies that examined outcomes of narrative writing instruction, all students demonstrated gains in number of story elements included. Four of the five students who exhibited internalizing behavior patterns in the Lane et al. (2010) study demonstrated additional gains in essay length and overall quality. This is in contrast to the findings of Little et al. (2010) where students with externalizing behavior patterns exhibited a greater number of gains in terms of all considered outcome measures. This discrepancy may be due to differences in writing genre or age of students as only elementary students were evaluated in terms of narrative writing strategy instruction (Adkins \& Gavins, 2012; Lane et al., 2010). Conversely, only secondary students were evaluated in terms of informative writing strategy instruction, where the author found gains in number of summary elements included as well as overall quality and total words written 


\section{THE NEBRASKA EDUCATOR, VOLUME 6}

(TWW) (Ennis, 2016). However, the findings from studies that included narrative or informative writing strategy instruction must be interpreted with caution because of very small sample sizes and a lack of replication with this population of students.

The effects of SRSD on students with EBD have thus far been analyzed based on grade level and writing genre. These effects can also be considered in terms of the educational setting where instruction took place. In the studies examined for this literature review, students received intervention in one of three settings: a typical public school, a special school for students with EBD, or a residential treatment facility (RTF). When aggregating the findings across these three settings, there are some small differences in the effects of treatment. For example, some or all of the students educated in public school settings in each study demonstrated increases in overall essay quality (Little et al., 2010; Mastropieri et al. 2014; Lane et al., 2010; Adkins \& Gavins, 2012; Mason \& Shriner, 2008). The majority of these students were at the elementary level, with only one of the five studies examining outcomes for secondary students in this setting (Mastropieri et al., 2014).

Further, this group included students both identified for and at risk of EBD. In comparison, students who received intervention in RTFs displayed gains in both quality and the number of included elements, either persuasive (Ennis et al., 2015; Ennis, Jolivette, \& Boden, 2013; Garwood et al., 2019) or informative/summary (Ennis, 2016). These added benefits may be explained by the difference in diagnosis, given that all students educated in RTFs were identified as having EBD as a prerequisite condition of entering the facility. The impact of SRSD instruction on students served in a special school was only examined in one of the ten studies (Mastropieri et al., 2009). Therefore, any conclusions drawn from it are limited by small sample size $(n=12)$ and a lack of replication for students taught in this particular educational setting. To 
THE NEBRASKA EDUCATOR, VOLUME 6

strengthen the validity of the current findings of this study, further research is necessary on the impact of SRSD instruction for students with EBD educated in special schools.

\section{Positive Behavior Interventions and Supports}

Finally, it is noteworthy to comment on the influence of Positive Behavior Interventions and Supports (PBIS) programs implemented within schools in addition to SRSD intervention. PBIS programs are based on a three-tiered model of supports, with each level providing an increasing amount of individualized support. At the first level, all students receive direct instruction in school-wide behavioral expectations such as being safe, responsible, and respectful (Sugai et al., 2000). Teachers, administrators, and other school personnel typically promote adherence to these expectations by rewarding exemplary behavior with positive reinforcement in the form of tokens or tickets. These are usually given in conjunction with behavior-specific praise about how the student is following school expectations. The tokens or tickets may then be used to "purchase" rewards such as computer time, extra recess, snacks, or other small prizes.

Data is collected on the implementation of these behavioral supports, and students who appear unresponsive to the primary tier of PBIS may receive secondary or tertiary supports. These supports include small group or potentially individualized instruction in social skills, anger management, or positive coping strategies. Progress is continuously monitored by way of direct observation and curriculum-based measurement, and students continue to receive behavioral supports according to their level of need in order to prevent or remediate possible internalizing or externalizing behavior patterns that may indicate potential risk for EBD (Sugai et al., 2000). In seven of the ten studies, participating schools had existing PBIS programs in place at the time of intervention (Little et al., 2010; Ennis et al., 2015; Mastropieri et al., 2009; Mastropieri et al., 2014; Lane et al., 2010; Ennis, 2016; Ennis, Jolivette, \& Boden, 2013). For the 


\section{THE NEBRASKA EDUCATOR, VOLUME 6}

remaining three studies (Garwood et al., 2019; Adkins \& Gavins, 2012; Mason \& Shriner, 2008), PBIS may have been implemented but this was not explicitly stated in the research findings. As these behavioral interventions were often delivered alongside specific strategy instruction in writing, the inclusion of such supports may account for some of the positive academic outcomes of SRSD in these cases. By establishing clear expectations and actively rewarding prosocial behavior, PBIS may have worked in conjunction with SRSD instruction to create an environment that was more conducive to learning for this population of students. However, without explicitly exploring the impact of SRSD on behavioral outcomes or controlling for the presence of an intervention with both academic and behavioral components, it is beyond the scope of this review to state, with any degree of certainty, that SRSD was responsible for gains in selfregulation skills. In order to make that claim, the included studies would need to have separate measures of specific behavioral outcomes in addition to the written expression outcome measures.

In summary, for the group of studies outlined in this review, self-regulated strategy development has proven to be an effective writing intervention for students at risk for or identified with emotional/behavioral disorders. The benefits of the intervention for this population remain fairly positive and consistent across several writing genres, including informative, persuasive, and narrative, at both elementary and secondary grade levels, and in different educational settings including typical public schools, private facilities specifically designed to teach students with EBD, and residential treatment facilities (RTFs). To strengthen these results, nine of the ten studies reported favorable ratings in terms of the social validity of the intervention by students and teachers (Adkins \& Gavins, 2012; Ennis, Jolivette, \& Boden, 2013; Ennis et al., 2015; Garwood et al., 2019; Lane et al., 2010; Little et al., 2010; Mason \& 


\section{THE NEBRASKA EDUCATOR, VOLUME 6}

Shriner, 2008; Mastropieri et al, 2009; Mastropieri et al., 2014). The only study that did not report favorable ratings of social validity at baseline and post-assessment (Ennis, 2016) showed no record of including such measures in the study design. 
THE NEBRASKA EDUCATOR, VOLUME 6

\section{References}

Adkins, M. H., \& Gavins, M. V. (2012). Self-regulated strategy development and generalization instruction: Effects on story writing and personal narratives among students with severe emotional and behavioral disorders. Exceptionality, 20(4), 235-249. https://doi.org/10.1080/09362835.2012.724625.

Ennis, R. P. (2016). Using self-regulated strategy development to help high school students with EBD summarize informational text in social studies. Education and Treatment of Children, 39(4), 545-568. https://doi:10.1353/etc.2016.0024.

Ennis, R., Jolivette, K., \& Boden, L. (2013). STOP and DARE: Self-regulated strategy development for persuasive writing with elementary students with E/BD in a residential facility. Education and Treatment of Children, 81-99. Retrieved April 21, 2020, from www.jstor.org/stable/42900213.

Ennis, R., Jolivette, K., Terry, N., Fredrick, L., \& Alberto, P. (2015). Classwide teacher implementation of self-regulated strategy development for writing with students with E/BD in a residential facility. Journal of Behavioral Education, 24(1), 88-111. https://doi.org/10.1007/s10864-014-9207-7.

Garwood, J., Werts, M., Mason, L., Harris, B., Austin, M., Ciullo, S., ... Shin, M. (2019). Improving persuasive science writing for secondary students with emotional and behavioral disorders educated in residential treatment facilities. Behavioral Disorders, 44(4), 227-240. https://doi.org/10.1177/0198742918809341.

Graham, S., McKeown, D., Kiuhara, S., \& Harris, K. R. (2012). A meta-analysis of writing instruction for students in the elementary grades. Journal of educational psychology, 104(4), 879. https://doi.org.libproxy.unl.edu/10.1037/a0029185. 


\section{THE NEBRASKA EDUCATOR, VOLUME 6}

Gresham, F. M., Lane, K. L., MacMillan, D.L., \& Bocian, K. M. (1999). Social and academic profiles of externalizing and internalizing groups: Risk factors for emotional and behavioral disorders. Behavioral Disorders,24,231-246. https://doi.org/10.1177/019874299902400303

Harris, K., \& Graham, S. (1996). Making the writing process work: Strategies for composition and self-regulation (2nd ed.). Cambridge: Brookline Books.

Harris, K. R., Graham, S., \& Mason, L. H. (2006). Improving the writing performance, knowledge, and motivation of struggling writers in second grade: The effects of selfregulated strategy development. American Educational Research Journal, 42, 295-340. https://doi.org/10.3102/00028312043002295.

Harris, K. R., Graham, S., Mason, L., \& Friedlander, B. (2008). Powerful writing strategies for all students. Baltimore: Brookes.

Lane, K., Graham, S., Harris, K., Little, M., Sandmel, K., \& Brindle, M. (2010). Story writing: The effects of self-regulated strategy development for second-grade students with writing and behavioral difficulties. The Journal of Special Education, 44(2), 107128. https://doi.org/10.1177/0022466908331044.

What Works Clearinghouse (2017). Self-Regulated Strategy Development. What Works Clearinghouse Intervention Report. Retrieved July 19, 2021, from https://ies.ed.gov/ncee/wwc/interventionreport/680.

Little, M., Lane, K., Harris, K., Graham, S., Story, M., \& Sandmel, K. (2010). Selfregulated strategies development for persuasive writing in tandem with schoolwide positive behavioral support: Effects for second-grade students with behavioral and 


\section{THE NEBRASKA EDUCATOR, VOLUME 6}

writing difficulties. Behavioral Disorders, 35(2), 157 -179.

https://doi.org/10.1177/019874291003500206.

Mason, L. H., \& Shriner, J. G. (2008). Self-regulated strategy development instruction for writing an opinion essay: Effects for six students with emotional/behavior disorders. Reading and Writing, 21(1-2), 71-93. https://doi.org/10.1007/s11145-0079065-y.

Mastropieri, M. A., Scruggs, T. E., Cerar, N. I., Allen-Bronaugh, D., Thompson, C., Guckert, M., ... \& Cuenca-Sanchez, Y. (2014). Fluent persuasive writing with counterarguments for students with emotional disturbance. The Journal of Special Education, 48(1), 17-31. https://doi.org/10.1177/0022466912440456.

Mastropieri, M., Scruggs, T., Mills, S., Cerar, N., Cuenca-Sanchez, Y., Allen-Bronaugh, D., ... Regan, K. (2009). Persuading students with emotional disabilities to write fluently. Behavioral Disorders, 35(1), 19-40.

https://doi.org/10.1177/019874290903500102.

Sugai, G., Horner, R. H., Dunlap, G., Hieneman, M., Lewis, T. J., Nelson, C. M., ... Ruef, M. (2000). Applying positive behavior support and functional behavioral assessment in schools. Journal of Positive Behavior Interventions, 2(3), 131-143. https://doi.org/10.1177/109830070000200302. 